\title{
The land carrying capacity and environmental risk assessment of livestock and poultry breeding considering crop planting
}

Nian Yang

Beijing Normal University

Lei Chen ( $\nabla$ chenlei1982bnu@gmail.com )

Beijing Normal University

Wenzhuo Wang

Beijing Normal University

Zhenyao Shen

Beijing Normal University

\section{Research Article}

Keywords: Agriculture, livestock and poultry breeding, land carrying capacity, combination of planting and breeding, Nonpoint source pollution

Posted Date: April 2nd, 2021

DOl: https://doi.org/10.21203/rs.3.rs-287695/v1

License: (9) This work is licensed under a Creative Commons Attribution 4.0 International License. Read Full License 
The land carrying capacity and environmental risk assessment of livestock and poultry breeding considering crop planting

Nian Yang ${ }^{\mathrm{a}}$, Lei Chen ${ }^{\mathrm{a},{ }^{*} \text {, Wenzhuo Wang }}{ }_{2}^{\mathrm{a}}$ Zhenyao Shen $^{\mathrm{a}}$

${ }^{a}$ State Key Laboratory of Water Environment Simulation, School of Environment, Beijing Normal University, Beijing 100875, P.R. China

Corresponding to: Lei Chen, Tel/fax: +861058807031.

E-mail address:chenlei1982bnu@bnu.edu.cn 
Abstract: At present, the contradiction between survival and ecology necessitates the integration of crop planting, chemical fertilizer application and livestock and poultry breeding. Reasonably integrated crop-livestock systems (ICLSs) have become an important part of regional ecological and agricultural development. In this study, the relationship between manure nutrient demands for crops and manure nutrient supply from livestock is considered based on the balance of ICLSs in Jiangxi Province, China. The land carrying capacity index and potential of livestock breeding under uncoordinated systems are further discussed. The study also addresses water environmental risk due to surplus nutrients by integrating a traditional land carrying capacity framework and hydrological model. The results show that phosphorus absorption in land areas is the main limiting factor for the development of the livestock and poultry industries. In addition, manure nutrient demand exceeded supply in most districts, while the unbalanced regions with nutrient pollution are located in the upper and middle reaches of the Ganjiang basin. In addition, expanding the crop demand for manure or increasing the manure collection rate will help reduce environmental harm; however, attention should be paid to the risk of excessive manure returns. Additional livestock manure can be transferred to regions with developed crop planting systems. This study supports more harmonious and common ICLSs construction.

Keywords: Agriculture; livestock and poultry breeding; land carrying capacity; combination of planting and breeding; Nonpoint source pollution

\section{Introduction}

Nowadays, the global agricultural system faces continual changes, including climate change, changes in demand for agricultural products, fluctuations in energy 
prices, and restrictions on land, water and other natural resources. Improving the efficiency of agricultural production without harming the environment and adapting to these changes is a universal requirement of all the nations of the world to achieve sustainable agricultural development (Jones et al.,2017). Recently, agricultural systems have become concentrated on specialized farms and there has been a dramatic growth in farm output to meet domestic and international market demands (Sulc \& Franzluebbers et al.,2014). Unfortunately, this growth accelerated the decoupling of crop and livestock production and caused a series of unintended negative environmental and ecological impacts, including soil erosion, water pollution and low crop diversity, leading to pest-related disasters (Peyraud et al.,2014; Hilimire.,2011; Russelle et al.,2007). The number of crop-livestock farms has been falling steadily in Europe (Ryschawy et al.,2017), Australia (Bell \& Moore., 2012) and the United States (Franzluebbers.,2007). The decoupling of crop and livestock systems has also occurred in China, a traditionally agricultural nation, with the number of rural households planting crops and raising livestock in recent decades declining from $71 \%$ in 1986 to only 12\% in 2017 (Jin et al.,2020). However, when designing systems, integrated croplivestock systems (ICLSs) have good potential based on their productivity in ecosystem functions and services; these systems utilize ecological interactions among crops and livestock to make agricultural ecosystems more efficient at cycling nutrients and preserving ecological functions and the environment, which are still highly marginalized worldwide (Bonaudo et al.,2014; Lemaire et al.,2014).

The separation of planting crops and raising livestock is obvious in China. The 
boom in livestock and poultry farms is stimulated by increasing population growth and living standards (Bai et al.,2018; Zhang et al. 2015b; Mueller et al.,2012; Tilman et al.,2011). The Food and Agriculture Organization (FAO) of the United Nations has reported that the current demand for protein has reached a total of $50 \%$ of the Chinese diet (Gu et al.,2019). The Ministry of Agriculture of China (MOA, 2018a) also predicted that consumption of meat will continue to grow in the next decade. Inevitably, the current high-cost pollutant control technology cannot keep up with the development of the livestock industry, leading to water environmental pollution, especially in rural China (Zhang et al. 2015a). On the other hand, chemical fertilizers, which have simple application processes and lead to higher yields than organic fertilizers, have become the driving force for grain growth, nutrients contributing at least $30 \%$ to $50 \%$, especially in areas with limited arable land (Stewart et al.,2005). More synthetic fertilizer has been used and manure application has decreased, owing to the decoupling of livestock and croplands (Zhang et al.,2019). The China Ministry of Agriculture projected "zero growth" of chemical fertilizer use by 2020 (MOA, 2015). However, chemical fertilizer applications are increasing annually, with their use in China accounting for $35 \%$ of the global consumption (Yin et al.,2018), causing water eutrophication and degradation of soil quality (Strokal et al., 2016). Given the pressure from the two major agricultural pollution sources, determining how to apply livestock-cropland systems is vital for sustainable development (Zhang et al.,2019).

Previous research has found that appropriately increasing manure fertilizer could improve crop yield and protect the environment at the scale of a field experiment 
(Hijbeek et al.,2016; Chen et al.,2014). However, there are still difficulties in the largescale implementation of this practice. Farmers' willingness to use manure has declined with the rising prices of rural labor, emigration of laborers to cities, implementation of regulation and policies by the government, and replacement of draught animals by machinery (Jin et al.,2020; Hilimire.,2011). Rebuilding the linkage between crop and livestock systems urgently requires some theoretical guidance, because integrated agriculture requires proficiency with both crops and livestock (Russelle et al.,2007). Previous studies have used the "pig/farmland ratio" (PFR) to reflect the degree of recoupling between livestock and croplands (Jin et al.,2020), the gray water footprint (GWF) to determine the dilution of livestock manure pollution (Yang et al., 2020), and the balance of nutrients in ICLSs to judge the carrying capacity (Wang et al.,2020). However, the current research on the supply and demand balance in ICLSs is still incomplete, lacking an understanding of livestock carrying capacity under different ratios and the risks to the water environment from the manure supply needed to meet crop demands.

The objectives of this paper are to (1) propose a set of risk assessment methods for water environments that integrate traditional land carrying capacity frameworks and watershed hydrological simulations and (2) quantify the risk of excessive pollution in typical agricultural regions under uncoordinated integrated crop-livestock systems and provide references for optimizing the management of livestock and poultry breeding in the future. 


\section{Material and Methods}

\subsection{Study area and data collection}

Jiang Xi Province in China was selected as the study area. The total grain output of Jiangxi Province was 21.9 million tons, ranking 13th in China according to the Bureau of Statistics of China. China, a large crop-producing nation, has only $8 \%$ of the world's arable land, feeding $18 \%$ of the global population, but consumes $1 / 3$ of the world's chemical fertilizers (Liu et al.,2019; Heffer \& Prud., 2008). As one of the traditionally agricultural provinces, Jiangxi Province has increased its use of fertilizers each year, reaching 1.436 million tons in 2015, compared to 1.032 million tons in 1993 (Liu \& Xie.,2018). In addition, the pollutants from livestock breeding, which are mostly distributed in regions with large amounts of animal products and relatively small areas of farmland, may exceed the local farmland carrying capacity in Jiangxi (Zheng \& Fu.,2011). In addition, although the proportion of water quality improvement is increasing, the annual mean total nitrogen and total phosphorus concentrations (the main pollutants) show significant upward trends from the 1980s to 2018 in Poyang Lake (Li et al.,2020). There is great potential for exploring integrated crop-livestock systems by gradually improving the waste resource utilization index to protect the environment in Jiangxi. Thus, this study concentrates on Jiangxi, a typical agricultural area, to guide the future development of ecological agriculture in China.

Jiangxi Province, the capital of which is Nanchang, is located in southeastern China and is composed of 11 districts and cities, including 100 districts and counties, 
and has five main rivers: Ganjiang, Fu River, Xinjiang, Raohe and Xiu Rivers (Fig. 1). The land area is approximately $166,900 \mathrm{~km}^{2}$, accounting for $1.74 \%$ of China. The region is dominated by plains and hills, and red soil is the most widely distributed zonal soil. The annual average temperature is approximately $18^{\circ} \mathrm{C}$, and the average annual precipitation is $1,341-1,940 \mathrm{~mm}$.

In this study, basic data on agricultural production were collected at the district scale in Jiangxi Province in 2016; the data collected included the types and yields of the main crops, the year-end inventory of livestock and poultry breeding, and the arable land area. In addition, basic raster data used in the model database, including DEM, land use, soil and weather data, were collected from the Geospatial Data Cloud website (http://www.gscloud.cn/sources/?cdataid=302\&pdataid=10), Resource and Environmental Sciences Data Center (http://www.resdc.cn/data.aspx?DATAID=184), and China Meteorological Network(http://data.cma.cn/site/index.html).

\subsection{SWAT model}

In this study, the Soil and Water Assessment Tool (SWAT) model was used to simulate the hydrology in Jiangxi. The SWAT model is a semi-distributed and physically based model developed by the United States Department of Agriculture (USDA); it includes hydrological modules, soil erosion and sediment transport modules, nutrient transport modules, and plant growth and operations management modules (Arnold et al.,2012; Neitsch et al.,2011). The SWAT model, which is used to simulate the quantity and quality of surface water and groundwater, relies on easily obtained data 
and has high calculation efficiency without requiring more time or money to calculate larger watersheds (Shen et al.,2012). The surface runoff was estimated using the modified Soil Conservation Service (SCS) curve number method (SCS, 1972), shown in formula (1) (Zhang et al.,2014).

$$
Q_{\text {surf }}=\frac{\left(\mathrm{R}_{\text {day }}-\mathrm{I}_{a}\right)^{2}}{\mathrm{R}_{d a y}-\mathrm{I}_{a}+S}
$$

where $Q_{\text {surf }}$ is the accumulated runoff or rainfall excess $\left(\mathrm{mm} \mathrm{H}_{2} \mathrm{O}\right) ; R_{\text {day }}$ is the rainfall depth for the day $\left(\mathrm{mm} \mathrm{H}_{2} \mathrm{O}\right) ; I_{a}$ is the initial abstraction, which includes surface storage, interception, and infiltration prior to runoff $\left(\mathrm{mm} \mathrm{H}_{2} \mathrm{O}\right)$; and $S$ is the retention parameter $\left(\mathrm{mm} \mathrm{H}_{2} \mathrm{O}\right)$.

\subsection{Land carrying capacity evaluation from the perspective of ICLSs}

Crop nutrient demands are calculated using crop yields and the nitrogen and phosphorus nutrient demands of the unit area of the crop yields under different crop types, as shown in formula (2). The nitrogen (phosphorus) nutrient requirements of different crops can be found in Table S1 (MOA,2018b; Zhang et al.,2015), sourced from the official website of the Ministry of Agriculture and FAO.

$$
N U_{N, P}=\frac{\sum_{i}^{n} P_{i} * C_{i}}{100}
$$

where $N U_{N, P}$ is the total amount of nitrogen (phosphorus) nutrient demand of all crops, $P_{i}$ is the yield of the $i$ th crop in the regions $\left(\mathrm{t} \cdot \mathrm{a}^{-1}\right)$, and $C_{i}$ is the nutrient requirement for the $i$ th crop to reach a yield of $100 \mathrm{~kg}\left(\mathrm{~kg} \cdot 100 \mathrm{~kg}^{-1}\right)$.

The crop manure nutrient demands come from livestock and poultry breeding, as calculated by formula (3). The ratio of the nutrients supplied the fertilizer to the total 
nutrient requirements of a crop $(F P)$ can be obtained based on the soil nutrient background content, which considers the contents of soil available phosphorus and soil total nitrogen in Jiangxi Province. According to the actual soil nitrogen and phosphorus survey results, the total nitrogen content of the arable land was greater than $1.2 \mathrm{~g} / \mathrm{kg}$ in 11 municipal districts (Table S2). The ratio of nitrogen nutrients supplied by fertilizer (FP of nitrogen) was 35\% (Table S3). The soil available phosphorus content is mainly distributed in the range of $10-40 \mathrm{mg} / \mathrm{kg}$. Thus, the comprehensive ratio of phosphorus nutrients supplied by fertilization ( $F P$ of phosphorus) was $48.45 \%$ (Table $\mathrm{S} 4$ ). The ratio of manure to fertilization $(M P)$ in different regions is usually determined according to actual local conditions. In this study, an $F P$ of $50 \%$ is used, which is the value provided by most Chinese agricultural technicians (Zhu et al.,2020; Li et al.,2016; Huang et al.,2006). In addition, nitrogen and phosphorus utilization efficiencies of manure and urine nutrients $(M R)$ of $30 \%$ and $35 \%$, respectively, were adopted, as recommended by the Ministry of Agriculture (MOA, 2017). Considering the developed agricultural practice in Jiangxi and the relatively high utilization of organic resources, the upper limit is selected as the value of $M R$.

$$
N U_{r . m}=\frac{N U_{N, P} * F P * M P}{M R}
$$

where $N U_{r . m}$ is the crop manure nutrient demand $\left(\mathrm{t} \cdot \mathrm{a}^{-1}\right), N U_{N, P}$ is the total nitrogen and phosphorus nutrient demand of all crops $\left(\mathrm{t} \cdot \mathrm{a}^{-1}\right), F P$ is the ratio of nutrients supplied by fertilization to the total nutrient requirements of the crop (\%), $M P$ is the ratio of nutrients supplied by manure to the total nutrients supplied by fertilization, and $M R$ is the utilization efficiency of the nutrients from manure and urine (\%). 
The manure nutrients supplied by livestock and poultry breeding accounts for the loss of nutrients in the processes of collection, treatment and storage, as calculated by formula (4). The livestock and poultry inventory was obtained from the statistical yearbook of Jiangxi, and the excretion coefficient is obtained from references (Wang et al.,2020; Jia et al.,2018; China,2009). The collection rate of livestock manure represents a comprehensive utilization rate, which is set as $87.8 \%$ based on local investigation. In addition, the nitrogen (phosphorus) retention rate in the process of manure collection and treatment was $62 \%(72 \%)$, as described by the Ministry of Agriculture in 2018 (MOA, 2018), under the conditions of solid manure composting, sewage storage in oxidation ponds, or farmland utilization after anaerobic fermentation. These treatments are similar to those used for livestock and poultry manure in Jiangxi Province (Yan et al., 2017).

$$
M_{S}=\sum_{i=1}^{n} A_{i} * E_{i} * G_{r} * S_{r}
$$

where $M_{s}$ is the manure nutrient supply from livestock and poultry breeding in the region $\left(\mathrm{t} \cdot \mathrm{a}^{-1}\right), A_{i}$ is the inventory of the $i$ th livestock or poultry species, $E_{i}$ is the annual nitrogen (phosphorus) excretion coefficient of the $i$ th livestock or poultry species $\left(\mathrm{kg} \cdot \mathrm{d}^{-}\right.$ $\left.{ }^{1}\right)$ (Table S5), $G_{r}$ is the collection coefficient in the region (\%), and $S_{r}$ is the nutrient retention rate, which is related to the treatment methods (\%).

The pig equivalent standard is a measurement unit used to determine the amount of nitrogen and phosphorus excreted by livestock and poultry, as shown in formula (5). This unit provides a more convenient basis for calculation and quantity comparisons. Pig equivalents, in which one pig is equivalent to one pig, can be used as measurement 
standards for calculating the amount of livestock and poultry breeding in regions (MOA, 2018). Then, the manure nutrient supply per pig equivalent is calculated based on the ratio of the total manure nutrient supply to the total pig equivalent value in the region (formula (6)).

$$
\begin{aligned}
Q & =\sum_{i=1}^{n} A_{i} * R_{i} \\
N S_{r, a} & =\frac{M_{s}}{\mathrm{Q}} * 1000
\end{aligned}
$$

where $Q$ is the actual inventory of the livestock and poultry breeding in the region (pig equivalent), $A_{i}$ is the inventory of the $i$ th livestock or poultry species, and $R_{i}$ is the conversion coefficient of the $i$ th livestock or poultry species to the pig equivalent. According to guidelines, 100 pigs $=15$ cows $=30$ beef cattle $($ draught cattle $)=250$ sheep $=2,500$ poultry $(\mathrm{MOA}, 2018) . N S_{r, a}$ is the manure nutrient supply per pig equivalent $(\mathrm{kg})$.

The land carrying capacity of livestock and poultry breeding refers to the largest stock of livestock and poultry that can be carried by cultivated land, woodland and grassland in regions with conditions suitable for sustaining terrestrial ecosystems. The theoretical maximum breeding quantity based on crop nutrient demands being met by manure (manure nutrient supply per pig equivalent) can be calculated by formula (7). In this study, the ratio of the actual number of livestock and poultry bred to the maximum breeding number is used to characterize the carrying capacity, as shown in formula (8). When the ratio is larger than 1.0, the number of livestock and poultry bred in the region is above carrying capacity.

$$
R=\frac{N U_{r, m}}{N S_{r, a}} * 1000
$$




$$
I=\frac{Q}{R}
$$

where $R$ is the theoretical maximum breeding quantity based on the crop nutrient demand being met by manure (pig equivalent) and $I$ is the index of the land carrying capacity of livestock and poultry breeding.

The potential carrying capacity of livestock and poultry breeding equals the difference between the theoretical maximum breeding level and the actual breeding level, calculated based on formula (9). This represents the extra amount of livestock breeding accommodated by the regional crop manure demand. However, the nutrient supply from livestock manure may exceed the crop nutrient demands in some districts and counties. If these excess nutrients are not handled properly and immediately, they can enter cultivated land systems. The extra farmland load, calculated by formula (10), is then used to characterize the pollution risk of cultivated land once crop nutrient demands are met by the manure.

$$
\begin{aligned}
& C=Q-R \\
& E_{\text {load }}=\frac{M_{S}-N U_{r . m}}{\text { Area } * 100}
\end{aligned}
$$

where $C$ is the potential carrying capacity of livestock and poultry breeding (pig equivalent), $E_{\text {load }}$ is the extra farmland load $\left(\mathrm{kg} \cdot \mathrm{hm}^{-2}\right)$, and Area is the arable land area in the district and county, extracted from a 2015 land use map of Jiangxi Province $\left(\mathrm{km}^{2}\right)$.

\subsection{Water environmental risk assessment using an integrated model and land capacity}

In this study, simulated hydrology and traditional land carrying capacity frameworks were integrated to calculate the concentrations of nitrogen and phosphorus 
in surface water at the subbasin scale using formula (11). Then, these concentrations are compared with the surface water environmental quality standards to characterize the risk level in each area. The study area was divided into 303 subbasins based on a DEM of the Poyang Lake basin, which covers almost the entire province. Furthermore, the additional manure nutrient supply was calculated after meeting crop nutrient demands based on the percentage of area in the district covered by the subbasin. Next, the additional pollutants from livestock breeding were further calculated to determine the pollutant load actually migrating into water bodies, and this value was combined with the farmland pollutant loss coefficient (12\%) (Wang et al., 2009).

$$
C_{\text {sub }}=\frac{M_{\text {sub }} * 12 \%}{W_{\text {sub }}}
$$

where $C_{\text {sub }}$ is the concentration of nitrogen (phosphorus) in surface water, $M_{\text {sub }}$ is the nitrogen (phosphorus) content in each subbasin $(\mathrm{kg})$, and $W_{\text {sub }}$ is the total runoff of each subbasin simulated by the SWAT model $\left(\mathrm{m}^{3}\right)$.

\section{Results}

\subsection{Analysis of the carrying capacity considering the supply and demand relationship}

Crop manure supply and demand analysis. The total nitrogen and phosphorus nutrients required by crops in the districts of Jiangxi Province are shown in Fig. 2 (a) and (d). The manure demands of crops are shown in Fig. 2 (b) and (e), and their spatial distribution is consistent with the crop nutrient demand. The crop nitrogen and phosphorus demands from manure range from 0-19930 $\mathrm{t}$ and 0-7066 t, with mean values 
of $4250 \mathrm{t}$ and $1551 \mathrm{t}$ per district, respectively, with the nitrogen fertilizer use being more than twice the phosphate fertilizer use. The result also reveals that the regions surrounding the lake tend to have higher manure nutrient demands due to the developed state of the planting industry. The crop growth in these regions benefit from better water and heat conditions, fertile soil, and large proportions of paddy and cultivated fields and are an important grain commodity source for China (Xie et al.,2016). The application of organic fertilizer can provide a variety of nutrients for crop production while protecting the environment (Hijbeek et al.,2016). However, in the districts with rapid urbanization, such as Xihu district and Qingyunpu district, the demand for crops is very low.

The nitrogen and phosphorus provided by livestock and poultry breeding are shown in Fig. 2 (c) and (f). These results indicate that a high manure supply from livestock is distributed near Poyang Lake, surrounding the middle reaches of the Ganjiang basin, similar to the overall distribution of the manure demand for crops (Fig. 2 (b) and (e)). The regions with high manure supply and demand include the counties of Gao'an, Taihe, Nanchang, Fengcheng, Ji'an, and Jinxian, as shown in Fig. 2 (c) and (f). To some extent, the distribution of livestock breeding in Jiangxi is more reasonable, owing to the consistency with manure demand for crops. The nitrogen and phosphorus contents in manure range from 0-9177 $t$ and 0-5998 $t$, with mean values of $2119 \mathrm{t}$ and $1430 \mathrm{t}$ per district, respectively. The comparison of the mean values of nutrient demand and supply per district showed that the manure nitrogen supply is insufficient and lower than the crop nitrogen demand (4250 t per district). The manure phosphorus supply is close to 
the crop phosphorus demand (1551 t per district). Thus, in most districts, phosphorus is more likely than nitrogen to contribute to livestock manure pollution.

The livestock analysis based on pig equivalent. the distribution of actual livestock in each region is shown in Fig. 3 (1) and is consistent with the spatial distribution of the manure nutrient supply (Fig. 2 (c) and (f)), where the southern area of Poyang Lake and the middle reaches of the Ganjiang basin tend to have higher concentrations of livestock and poultry farms. High values of livestock breeding are distributed in the cities of Nanchang, Yichun, and Ji'an, with a range of 0.874-1.322 million pig equivalents. Among them, Gao'an city has the largest value, with 1.322 million pig equivalents. The manure nutrient supply per pig equivalent are shown in Fig. 3 (2) and (3). The nitrogen nutrients per pig equivalent ranged from 5-8 kg, with a mean value of $6.47 \mathrm{~kg}$. The phosphorus nutrients per pig equivalent ranged from 4$5.5 \mathrm{~kg}$, with a mean value of $4.38 \mathrm{~kg}$; this value is lower than the nitrogen nutrient supply per pig equivalent and is related to the lower phosphorus content in livestock excretions. The spatial distribution shows that high values of nitrogen content per pig equivalent are mostly distributed in the middle reaches of the Ganjiang basin and the upper reaches of the Fu River basin (Fig. 3 (2)), while phosphorus is more widely distributed, including around Poyang Lake, as shown in Fig. 3 (3). Obviously, the value provided by the pig equivalent unit is relatively stable, although there are fluctuations within a small range. These fluctuations are related to the type and methods of feeding, technological processes used, and manure disposal methods of the livestock and poultry breeding industry in the actual region (MOA,2018; Philippe et 
al.,2011).

The theoretical livestock maximums based on the land carrying capacity for crop nutrient requirements are shown in Fig. 4 (I) and (II). As Fig. 4. (I) shows, there is a relatively high livestock carrying capacity near Poyang Lake (including in Poyang, Nanchang, and Yugan Counties and the cities of Fengcheng, Gao'an, and Linchuan), with more than 1.7 million pig equivalents. The average livestock carrying capacity of each district is 0.636 million pig equivalents based on nitrogen. However, based on phosphorus, the livestock carrying capacity is in the range of $0-1.413$ million pig equivalents, with a mean value of 0.343 million in each district (Fig. 4 (II)), close to $1 / 2$ of the mean value of nitrogen. These findings may be related to the lower demand for phosphorus by crops, resulting in relatively low theoretical carrying capacity and indicating that phosphorus pollution is a key factor in local livestock restriction. A previous study proved that phosphorus levels would be elevated by the long-term application of phosphorus fertilizer and animal wastes, leading to eutrophication (Carpenter.,2008).

In addition, the livestock carrying capacity index, calculated based on nitrogen and phosphorus, is shown in Fig. 4 (III) and (IV), respectively. The index value in Dongxiang, Xinfeng and Longnan Counties is higher than 1.0 in Fig. 4 (III), indicating higher risk, though the livestock carrying capacity index is lower than 1.0 among most regions. The potential risk reflected by the index calculated based on phosphorus was more severe than that calculated based on nitrogen, as shown in Fig. 4 (IV). Except for key regions exceeding 1.0 (consistent with the distribution of nitrogen), there are 
different degrees of elevated risks along the Ganjiang basin and the Xinjiang Basin, including Ganzhou, Pingxiang, Yichun, Ji'an and Nanchang cities. The soil in these regions is fertile, with soil available phosphorus ranging from $20-35 \mathrm{mg} / \mathrm{kg}$, according to local investigations, which suggests reduced phosphorus demand from livestock manure. Thus, more attention should be paid to phosphorus nutrient inputs from livestock manure when developing ICLSs (Daniel et al.,1998).

The theoretical breeding potential of livestock based on nitrogen and phosphorus nutrients, respectively, are shown in Fig. 5 (m) and (n). Apparently, regions surrounding Poyang Lake and the middle reaches of the Rao River basin can accommodate more livestock, which is related to the locally high manure nutrient demand by crops in ICLSs. The negative values shown in the south and west of Jiangxi, including the Ganjiang basin and eastern Xinjiang basin, indicate that plans in these regions should consider the currently existing livestock breeding level. It may be good for ecological agriculture to migrate manure into districts with high manure nutrient demand for crops, such as regions near Poyang Lake. Although previous governmental measures were implemented to move the livestock breeding industry out of the areas surrounding the lake by delimitating restricted regions to prevent water pollution, the benefits of ICLSs cannot be ignored (Bell \& Moore., 2012). A previous study pointed out that the manure fertilizer produced in the southern region can be appropriately transported to regions with more developed planting systems, such as the central and northern regions of Jiangxi Province, to solve manure pollution problems (Jia et al.,2015). 
The distribution of the extra farmland loads after meeting the manure nutrient demand of crops are shown in Fig. 5 (o) and (p), where negative values represent areas not experiencing pressure from extra manure; the smaller the negative value is, the lower the pressure from farmland pollution. Positive values represent pressure on the farmland from extra manure, and the greater the positive value is, the greater the manure load per unit of farmland. The nitrogen balance between crop planting and livestock breeding is shown in Fig. 5 (o). Southern Ganzhou city experiences relatively high farmland nutrient pollution, with excess manure nutrients ranging from $32-69 \mathrm{~kg} \cdot \mathrm{hm}^{-2}$, with an average of $44 \mathrm{~kg} \cdot \mathrm{hm}^{-2}$. However, the results based on the phosphorus balance show that more farmlands need to decompose excessive phosphorus nutrients input, as shown in Fig. 5 (p). The results also include Dongxiang, Ji'an, Taihe and Guangfeng Counties (excluding southern Ganzhou), with values ranging from $25-75 \mathrm{~kg} / \mathrm{hm}^{2}$. Reasonably planning for and controlling excess manure nutrients in cultivated land is necessary in ICLSs (Svanbäck et al.,2019). In particular, the additional absorption by farmland of phosphorus creates greater risk prevention and control challenges for local water environments.

\subsection{Water environmental risk assessment}

This study combines hydrological data of major river basins from 2009 to 2018 for use in the simulation. The years from 2009-2013 serve as the calibration period and those from 2014-2018 serve as the verification period. The coefficient of determination $\left(R^{2}\right)$ and Nash-Sutcliffe efficiency (NSE; Nash and Sutcliffe,1970) index both show 
good results, with values exceeding 0.75 (Fig. 6). The concentrations of total nitrogen and phosphorus in each subbasin are shown in Fig. 7 (r) and (s), respectively, with 303 subbasins. Negative values indicate that regions can achieve a balance between crops and livestock with no excess pollution emissions, owing to the manure nutrient demand of crops and livestock manure supply. The water environmental risk assessment was conducted by comparing the results of the total nitrogen and phosphorus concentrations with surface water environmental quality standards. Fig. 7. (r) shows that the southern Ganjiang basin, including Xinfeng and Longnan Counties, consists of type IV water, with great risk of exceeding the standards, which needs to be considered when applying manure. However, the phosphorus pollution in water bodies is more serious than the nitrogen pollution (Fig. 7 (s)). The regions with high concentrations of phosphorus (> $0.4 \mathrm{mg} \cdot \mathrm{L}^{-1}$ ) are distributed in the southern and central areas of the Ganjiang basin, mainly in Ganzhou and Ji'an cities, including Xinfeng, Longnan, Taihe, Ji'an, and Anfu counties. Among these locations, the water is classified as inferior to type $\mathrm{V}$ water. The aquatic environments in these areas have greater risks than those in other areas, which indicates that the scale of livestock and poultry breeding needs to be further optimized. According to the spatial distribution of nitrogen and phosphorus concentrations at the subbasin scale, the surface water quality of most subbasins is type III $(\mathrm{TN} \leq 1.0$ $\mathrm{mg} / \mathrm{L} ; \mathrm{TP} \leq 0.2 \mathrm{mg} / \mathrm{L}$ ), meeting the surface water environmental quality requirements of Jiangxi. To some extent, these regions can achieve the combination of planting and livestock and poultry breeding. However, the upper and middle reaches of the Ganjiang watershed need to focus on the risk of excessive phosphorus pollution caused by the 
development of livestock and poultry breeding industries in the future. Livestock manure can be highly processed to produce organic fertilizer. Then, this fertilizer can be transported to regions with developed planting industries, such as Poyang Lake, thus taking advantage of regional resource integration (Jia et al.,2015).

\section{Discussion}

\subsection{Changing nutrient demand and supply affect environmental risk}

Many factors influence the crop-livestock system, including the willingness of rural residents to participate, manure treatment technology, natural resources, policy and management (Jin et al.,2020; Ryschawy et al.,2017; Hilimire.,2011; Franzluebbers.,2007). Among these, the proportion of crop demand and the proportion of manure returned to the field are the two most direct impacts. Thus, this study focuses on these two aspects to further explore their impact.

At present, the return rate of livestock manure to the field has become a critical factor in achieving nutrient cycling in ICLSs. This study combines the characteristics of domestic and foreign livestock manure practices, with return rates of $30 \%, 40 \%, 50 \%$, $60 \%$, and $70 \%$, to explore the number of districts and counties where the manure supply exceeds the farmland demand (Bai et al., 2016; Gu et al., 2015). The numbers of districts and counties where the manure supply exceeds the crop manure demand are shown in Fig. 8. This result indicates that the amount of chemical fertilizers used in crop fertilization has decreased and that the proportion of organic fertilizer has increased, resulting in the number of districts exceeding the land carrying capacity 
declining. Phosphorus pollution was more severe than nitrogen pollution in Jiangxi, as shown in Fig. 8, which was related to the low demand for phosphate fertilizer by crops and the large amount of phosphorus produced by livestock manure. To set a reasonable rate of return of livestock manure to the field, it is necessary to fully consider the impact of multiple factors, such as local planting and breeding patterns, soil nutrients, crop demands, and the impact of manure on food (Yang et al., 2017). Blindly returning all manure to the field may cause a soil nutrient surplus, leading to serious water environment risks. Therefore, exploring the optimal ratio of livestock manure return to the field will be necessary in the future.

Besides, the supply of manure nutrients, which determines the nutrient input, is also an important part of ICLSs. The annual excretion of livestock varies greatly due to species, growth period, feed, management level, climate, and other reasons (Bao et al., 2019). The manure collection rate was set in the range of 50\%-95\%, combined with the current situation of large-scale livestock breeding farms being the dominant farm type in China (Bai et al., 2018), to quantitatively characterize the possible pollutant discharge amount caused by different collection rates. The pollutant discharge amount decreased as the collection rate increased overall, as shown in Fig. 9. The pollutants directly discharged into the environment declined with increasing collection rate. However, the collected manure will indirectly cause a soil nutrient surplus once it exceeds the nutrient demands of crops, as it likely flows into water bodies due to the process of soil erosion. This phenomenon is especially apparent in the results for phosphorus (Fig. 8). This finding forces us to pay attention to the pollution caused by 
the surplus in nutrients returned to fields as collection rates continuously improve and to realize that the manure demand for crop production is very meaningful for preventing arable land from exceeding the land carrying capacity and pollution from exceeding water environmental quality standards (Zhang et al., 2019). In addition, both the collection rate and the nutrient retention rate of livestock affect the manure nutrient supply for crops. Livestock manure is mainly treated by composting, sewage oxidation pond storage or farmland utilization after anaerobic fermentation in China (Yan et al., 2017; Dong et., 2020). These methods can be combined with pollutant monitoring of breeding facilities to further explore their impact on ICLSs in the future.

\subsection{Shortcomings and understanding of ICLSs}

Farming and breeding are integrated in crop-livestock-forestry systems (de Carvalho et al., 2019) more widely globally than in China. In China, integrated systems focus more on the utilization of livestock and poultry manure, ignoring the impact of the coupling of livestock manure nutrients, soil nutrients, and chemical fertilizers on food production (Iqbal et al., 2019), which has attracted attention. In the current mode of controlling livestock and poultry pollution, the livestock breeding industry has been required to move away from rivers, while regions with developed planting industries are often close to rivers, causing a series of problems, such as difficulties in livestock and poultry manure collection and transportation costs (Bai et al., 2016). Exploring the compatibility of farmland and livestock breeding farms in ICLSs and how to achieve coupling of planting and breeding in the same area is one issue that urgently needs to 
be focused on in the future. It is necessary to further the exploration of phosphate fertilizers in the future.

ICLSs, which rely on internal circulations, are an environmentally friendly way to ensure food production under limited resources and have received attention from an increasing number of countries and regions (Lemaire et al.,2014; Bonaudo et al.,2014). However, the current evaluation system for ICLSs is not perfect, lacking evaluation indicators for the effects of internal coupling, and more attention has been paid to land carrying capacity (Zhu et al., 2020). Moreover, the estimation of risks to water environments has mostly been performed through empirical modeling (Yang et al., 2020), with research on the mechanisms driving the relationship between ICLSs and the water environment lacking. Thus, a mechanism-based model, combining terrain, rainfall, soil and other factors, is needed in the future to further analyze the process by which livestock pollution enters water bodies. In addition, the basic assumption is that all the nutrients returned to fields are first absorbed by crops, and then the excess is drained out, ignoring the impact of the rainy season. The impact of rainfall needs to be further refined and considered spatially and temporally to evaluate the effects of ICLSs; this effect can also be studied with a mechanism-based model.

\section{Conclusion}

In this study, the relationship between the manure nutrient demands of crops and manure nutrient supply from livestock were investigated and the environmental impact caused by the uncoordinated crop-livestock systems was assessed. The results showed 
that crop-livestock systems were relatively balanced regionally, somewhat unbalanced, especially in Dongxiang, Xinfeng and Longnan Counties. From the results of nitrogen and phosphorus nutrients calculated, phosphorus pollution was the main limiting factor for local livestock and poultry breeding, with more serious risks to land carrying capacity and the water environment, than excess nitrogen nutrient loads. Hotspots is in the southern and central areas of the Ganjiang basin. And nutrient transfer between regions will help to alleviate the risk in hotspots with high pollutant loads. For the joint analysis of nutrient demand and supply changed, it found that increasing in the ratio of manure collected or crop nutrient demands are both beneficial for solving livestock pollution problems. However, the risks of excessive amounts of feces being returned to fields need to be clear. In the future, it is necessary to vigorously explore the specific practical measures of the integrated crop-livestock systems, and be alert to environmental risks caused by uncoordinated systems.

\section{Declarations}

\section{- Ethical approval and consent to participate}

Farming data is obtained from the Agriculture and Rural Affairs Bureau of JiangXi province. Thus, the ethics approval and consent to participate are both not required for this paper.

\section{- Consent for publication}

Written informed consent for publication was obtained from all participants.

- Availability of data and materials

The datasets used or analysed during the current study are available from the corresponding author on reasonable request.

\section{- Competing interests}


The authors declare that there are no conflicts of interest regarding this manuscript.

\section{- Funding}

This research was funded by the National Natural Science Foundation of China (No. 51779010), the Fund for Innovative Research Group of the National Natural Science Foundation of China (No. 51721093), and the Interdiscipline Research Funds of Beijing Normal University.

\section{- Authors' contributions}

Nian yang: Conceptualization, Software, Writing - Original Draft; Lei Chen: Writing- Reviewing and Editing, Methodology; Wenzhuo Wang: Investigation, Visualization, Data curation; Zhenyao Shen: Supervision, Resources.

\section{- Acknowledgements}

This paper is supported by the National Natural Science Foundation of China (No. 51779010), the Fund for Innovative Research Group of the National Natural Science Foundation of China (No. 51721093), and the Interdiscipline Research Funds of Beijing Normal University. Data used in this study are available from the publications and local administrative agency cited therein. The authors want to thank the Agriculture and Rural Affairs Bureau of JiangXi province for their data support.

\section{Reference:}

Arnold JG, Moriasi DN, Gassman PW, Abbaspour KC, et al (2012) SWAT: Model Use, Calibration, and Validation. Trans ASABE 55 , 1491-1508. $\underline{\text { doi: } 10.13031 / 2013.42256}$

Bai Z, Ma W, Ma L, Velthof GL, Wei Z, et al (2018) China's livestock transition: 
Driving forces, impacts, and consequences. Sci Adv 4, eaar8534. https://doi.org/10.1126/sciadv.aar8534

Bai Z, Ma L, Jin S, Ma W, Velthof G L, et al (2016) Nitrogen, Phosphorus, and Potassium Flows through the Manure Management Chain in China. Environ Sci Technol 50, 13409-13418. https://doi.org/10.1021/acs.est.6b03348

Bao WQ, Yang Y, Fu TC, Xie GH (2019) Estimation of livestock excrement and its biogas production potential in China. J Clean Prod 229, 1158-1166. https://doi.org/10.1016/j.jclepro.2019.05.059

Bell LW \& Moore AD (2012) Integrated crop-livestock systems in Australian agriculture: Trends, drivers and implications. Agric $\quad$ Syst 111, 1-12. doi:10.1016/j.agsy.2012.04.003

Bonaudo T, Bendahan AB, Sabatier R, Ryschawy J, Bellon S, et al (2014) Agroecological principles for the redesign of integrated crop-livestock systems. Eur J Agron 57, 43-51. doi:10.1016/j.eja.2013.09.010

Carpenter SR (2008) Phosphorus control is critical to mitigating eutrophication. PNAS 105, 11039-11040. doi:10.1073/pnas.0806112105

Chen XP, Cui ZL, Fan MS, Vitousek P, Zhao M, et al (2014) Producing more grain with lower environmental costs. Nature 514, 486-489. doi:10.1038/nature13609

Dong SS, Sui B, Shen YJ, et al (2020) Investigation and analysis of the linkage mechanism and whole process cost of livestock manure organic fertilizer. Int $\mathrm{J}$ Agric Biol Eng 13, 223-227. sci-hub.se/10.25165/ijabe.v13i2.5682

Daniel TC, Sharpley AN, Lemunyon JL (1998) Agricultural phosphorus and 
eutrophication: A symposium overview. J Environ Qual 27, 251-257. https://doi.org/10.2134/jeq1998.00472425002700020002x

Gu BJ, Zhang XL, Bai XM, Fu BJ \& Chen DL (2019) Four steps to food security for swelling cities. Nature 566, 31-33. doi:10.1038/d41586-019-00407-3

Gu BJ, Ju XT, Chang J, Ge Y \& Vitousek PM (2015) Integrated reactive nitrogen budgets and future trends in China. PNAS 112, 8792-8797. doi:10.1073/pnas. 1510211112

Franzluebbers AJ (2007) Integrated crop-livestock systems in the southeastern USA. Agron J 99 361-372. https://doi.org/10.2134/agronj2006.0076

Heffer P \& Prud HM (2008) World agriculture and fertilizer demand, global fertilizer supply and trade 2008-2009 summary report. Vietnam: HoChiMinh City. International Fertilizer Industry Association (IFA). In 34th IFA Enlarged Council Meeting, Ho Chi Minh City, Vietnam

Hilimire K (2011) Integrated Crop/Livestock Agriculture in the United States: A Review. J Sustain Agr 35, 376-393. doi:10.1080/10440046.2011.562042

Hijbeek R, Van Ittersum MK, Ten Berge HFM, Gort G, Spiegel H \& Whitmore AP (2016) Do organic inputs matter-a meta-analysis of additional yield effects for arable crops in Europe. Plant Soil 411, 293-303. doi:10.1007/s11104-016-3031-X

Huang HX, Li ST, Li XL, et al (2006) Analysis on the status of organic fertilizer and its development strategies in China. Soils and Fertilizers 1, 3-8

Iqbal A, He L, Khan A, Wei S, Akhtar K, Ali I, et al (2019) Organic Manure Coupled with Inorganic Fertilizer: An Approach for the Sustainable Production of Rice by 
Improving Soil Properties and Nitrogen Use Efficiency. Agronomy 9, 651. doi:10.3390/agronomy9100651

Jin SQ, Zhang B, Wu B, Han DM, Hu Y, Ren CC, et al (2020) Decoupling livestock and crop production at the household level in China. Nat Sustain 4, 48-55. doi:10.1038/s41893-020-00596-0.

Jia W, Qin W, Zhang Q, Wang X, Ma Y \& Chen Q (2018) Evaluation of crop residues and manure production and their geographical distribution in China. J Clean Prod 188, 954-965. doi:10.1016/j.jclepro.2018.03.300

Jia W, Yan ZJ, Chadwick DR, et al (2015) Integrating soil testing phosphorus into environmentally based manure management in peri-urban regions: a case study in the Beijing area. Agric Ecosyst Environ 209, 47-59. https://doi.org/10.1016/j.agee.2015.04.028

Jones JW, Antle JM, Basso B, Boote KJ, et al (2017) Toward a new generation of agricultural system data, models, and knowledge products: State of agricultural systems science. Agric Syst 155, 269-288. doi:10.1016/j.agsy.2016.09.021

Lemaire G, Franzluebbers A, de Faccio Carvalho PC, et al (2014) Integrated croplivestock systems: Strategies to achieve synergy between agricultural production and environmental quality. Agric Ecosyst Environ 190, 4-8. https://doi.org/10.1016/j.agee.2013.08.009

Li ST, Liu XY, Ding WC (2016) Estimation of organic nutrient sources and availability for land application. Better Crops 100, 4-6

Liu G \& Xie H (2018) Simulation of Regulation Policies for Fertilizer and Pesticide 
Reduction in Arable Land Based on Farmers' Behavior-Using Jiangxi Province as an Example. Sustainability 11, 136.doi:10.3390/su11010136

Liu YF, Sun DS, Wang HJ, Wang XJ, et al (2019) An evaluation of China's agricultural green production: 1978-017. J Clean Prod 243,118483. doi:10.1016/j.jclepro.2019.118483

Ministry of Agriculture of China (MOA) (2018a) China Agriculture Outlook Report (2018-2027). China Agricultural Science and Technology Press, Beijing (In Chinese)

Ministry of Agriculture of China (MOA) (2018b) The Technical Guidelines for Measuring the Bearing Capacity of Soil Contaminated by Livestock and Poultry Manure (In Chinese)

Ministry of Agriculture of China (MOA) (2017) Technical Guide for Calculating the Land Carrying Capacity. China Agriculture Press, Beijing (In Chinese)

Ministry of Agriculture of China (MOA) (2015) Notification by the Ministry of Agriculture on the Issuance of a Zero Increase Action Plan on Fertilizer Use by 2020 and a Zero Increase Action Programme on Pesticide Use by 2020 (In Chinese)

Mueller ND, Gerber JS, Johnston M, Ray DK, Ramankutty N \& Foley JA (2012) Closing yield gaps through nutrient and water management. Nature 490, 254-257. $\underline{\text { doi:10.1038/nature } 11420}$

Nash JE \& Sutcliffe JV (1970) River flow forecasting through conceptual models part I-A discussion of principles. J Hydrol 10, 282-290. doi:10.1016/0022$\underline{1694(70) 90255-6}$ 
Neitsch SL, Arnold JG, Kiniry JR, et al (2011) Soil and water assessment tool theoretical documentation version 2009. Texas Water Resources Institute

Peyraud JL, Taboada M, Delaby L (2014) Integrated crop and livestock systems in Western Europe and South America: a review. Eur J Agron 57, 31-42. https://doi.org/10.1016/j.eja.2014.02.005

Philippe FX, Cabaraux JF \& Nicks B (2011) Ammonia emissions from pig houses: Influencing factors and mitigation techniques. Agric Ecosyst Environ 141, 245260. doi:10.1016/j.agee.2011.03.012

Ray DE, Schaffer HD (2005) How federal farm policy influences the structure of our agriculture. Online research publication. Knoxville, TN: Agricultural Policy Analysis Center. Retrieved online June 5, 2010

Russelle MP, Entz MH, Franzluebbers AJ (2007) Reconsidering integrated croplivestock systems in North America. Agron $\quad \mathrm{J} \quad$ 99, 325-334. https://doi.org/10.2134/agronj2006.0139

Ryschawy J, Martin G, Moraine M, Duru M \& Therond O (2017) Designing croplivestock integration at different levels: Toward new agroecological models? Nutr Cycl Agroecosyst 108, 5-20. doi:10.1007/s10705-016-9815-9

SCS, Us (1972) National engineering handbook, section 4: hydrology USPGO, Washington.

Shen ZY, Chen L, Liao Q, et al (2012) Impact of spatial rainfall variability on hydrology and nonpoint source pollution modeling. $\mathrm{J} \quad$ Hydrol 472, 205-215. https://doi.org/10.1016/j.jhydrol.2012.09.019 
Stewart WM, Dibb DW, Johnston AE \& Smyth TJ (2005) The Contribution of Commercial Fertilizer Nutrients to Food Production. Agron J 97, 1 . doi:10.2134/agronj2005.0001

Strokal M, Ma L, Bai Z, Luan S, Kroeze C, et al (2016) Alarming nutrient pollution of Chinese rivers as a result of agricultural transitions. Environ Res Lett 11, 024014. $\underline{\text { doi: } 10.1088 / 1748-9326 / 11 / 2 / 024014}$

Svanbäck A, McCrackin ML, Swaney DP, Linefur H, Gustafsson BG, Howarth RW \& Humborg C (2019) Reducing agricultural nutrient surpluses in a large catchmentLinks to livestock density. Sci Total Environ 648, 1549-1559. doi:10.1016/j.scitotenv.2018.08.194

Sulc RM \& Franzluebbers AJ (2014) Exploring integrated crop-livestock systems in different ecoregions of the United States. Eur J Agron 57, 21-30. doi:10.1016/j.eja.2013.10.007

The Group of Pollution Discharging Coefficient in the National Aquaculture Pollution Census in China (2009) The emission coefficient manual of the first national pollution census

Tilman D, Balzer C, Hill J \& Befort BL (2011) Global food demand and the sustainable intensification of agriculture. PNAS 108, 20260-20264. doi:10.1073/pnas.1116437108

Wang B, Huang Y, Liu W, et al (2020) Returning excrement from livestock, poultry, and humans to farmland as nutrient resources for crop growth: Assessment of rural China. Process Saf. Environ Protect 146, 412-423. 
https://doi.org/10.1016/j.psep.2020.09.001

Wang XY, Zhang YF, Ou Y (2009) Economic Loss Caused by Non-point Source Pollution A Case Study of Taishitun Town, Upper Catchment of Miyun Reservoir, Beijing. Journal of Ecology and Rural Environment 25, 37-41 (In chinese)

Xie HL, He YF, Zou JL \& Wu Q (2016) Spatio-temporal difference analysis of cultivated land use intensity based on emergy in the Poyang Lake Eco-economic Zone of China. J Geogr Sci 26, 1412-1430. doi:10.1007/s11442-016-1335-7

Yang J, Wang Y, Fang S, Qiang Y, Liang J, Yang G \& Feng Y (2020) Evaluation of livestock pollution and its effects on a water source protection area in China. Environ Sci Pollut Res 27, 18632-18639. doi:10.1007/s11356-019-06485-0

Yan J, de Buisonjé FE, Melse RW (2017) White paper. Livestock Manure Treatment Technology of the Netherlands and Situation of China. Wageningen Livestock Research, Report 1048. https://doi.org/10.18174/423982

Yang Y, Zhang H, Qian X, Duan J \& Wang G (2017) Excessive application of pig manure increases the risk of $\mathrm{P}$ loss in calcic cinnamon soil in China. Sci Total Environ 609, 102-108. doi:10.1016/j.scitotenv.2017.07.149

Yin H, Zhao W, Li T, Cheng X \& Liu Q (2018) Balancing straw returning and chemical fertilizers in China: Role of straw nutrient resources. Renew Sust Energ Rev 81, 2695-2702. doi:10.1016/j.rser.2017.06.076

Zhang C, Liu S, Wu S, et al (2019) Rebuilding the linkage between livestock and cropland to mitigate agricultural pollution in China. Resour Conserv Recycl 144, 65-73. sci-hub.se/10.1016/j.resconrec.2019.01.011 
Zhu N, Cao B, Qin F (2020) Analysis of land carrying capacity of livestock and poultry breeding in China from the perspective of combination of planting and raising[C]//IOP Conference Series: Earth and Environmental Science. IOP Publishing 585, 012085. doi:10.1088/1755-1315/585/1/012085.

Zhang T, Ni JP \& Xie DT (2015a) Severe situation of rural nonpoint source pollution and efficient utilization of agricultural wastes in the Three Gorges Reservoir Area. Environ. Sci Pollut Res 22, 16453-16462. doi:10.1007/s11356-015-5429-Z

Zhang X, Davidson EA, Mauzerall DL, Searchinger TD, Dumas P \& Shen Y (2015b) Managing nitrogen for sustainable development. Nature 528, 51-59. $\underline{\text { doi:10.1038/nature15743 }}$

Zhang CZ, Liu S, Wu SX, Jin SQ, et al (2019) Rebuilding the linkage between livestock and cropland to mitigate agricultural pollution in China. Resour Conserv Recycl 144, 65-73. sci-hub.se/10.1016/j.resconrec.2019.01.011

Zhang PP, Liu RM, Bao Y, Wang J, Yu W \& Shen ZY (2014) Uncertainty of SWAT model at different DEM resolutions in a large mountainous watershed. Water Res 53, 132-144. doi:10.1016/j.watres.2014.01.018

Zheng N \& Fu C (2011) Research on Non-Point Source Pollution Resulted from Livestock Breeding in Jiangxi Province. Adv Mat Res 356-360, 2344-2348. doi:10.4028/www.scientific.net/amr.356-360.2344

\section{Figure captions:}

Figure. 1. Geographical Location of Jiangxi Province. 
Figure. 2. The crop nitrogen and phosphorus nutrient demands are shown in (a) and (d); the manure nitrogen and phosphorus nutrient demands for crop growth are shown in (b) and (e); and the manure nitrogen and phosphorus nutrient supplies are shown in (c) and (f).

Figure. 3. The final inventory of each district and county converted to pig equivalent units in 2016 is shown in (1); the nitrogen and phosphorus nutrient contents per pig equivalent are shown in (2) and (3), respectively.

Figure. 4. The theoretical maximum livestock based on the land carrying capacity and considering nitrogen and phosphorus nutrition are shown in (I) and (II); the carrying capacity indexes considering nitrogen and phosphorus nutrition are shown in (III) and (IV), respectively.

Figure. 5. The breeding potential of livestock and poultry based on the calculation of nitrogen and phosphorus nutrient demand and supply are shown in (m) and (n) (pig equivalent). The excess units of farmland loads of nitrogen and phosphorus nutrients in each district are shown in (o) and (p), $\mathrm{kg} / \mathrm{hm}^{2}$.

Figure. 6. Results of hydrological calibration and validation in the Ganjiang, Xinjiang and Fu Rivers.

Figure. 7. The distribution of nitrogen and phosphorus concentrations in the water environment under additional livestock manure loads are shown in (r) and (s), respectively.

Figure. 8. The number of districts exceeding the land carrying capacity under different ratios of manure supply to fertilization. 
Figure. 9. Discharge amounts of total nitrogen and total phosphorus under different manure collection coefficients. 


\section{Figures}

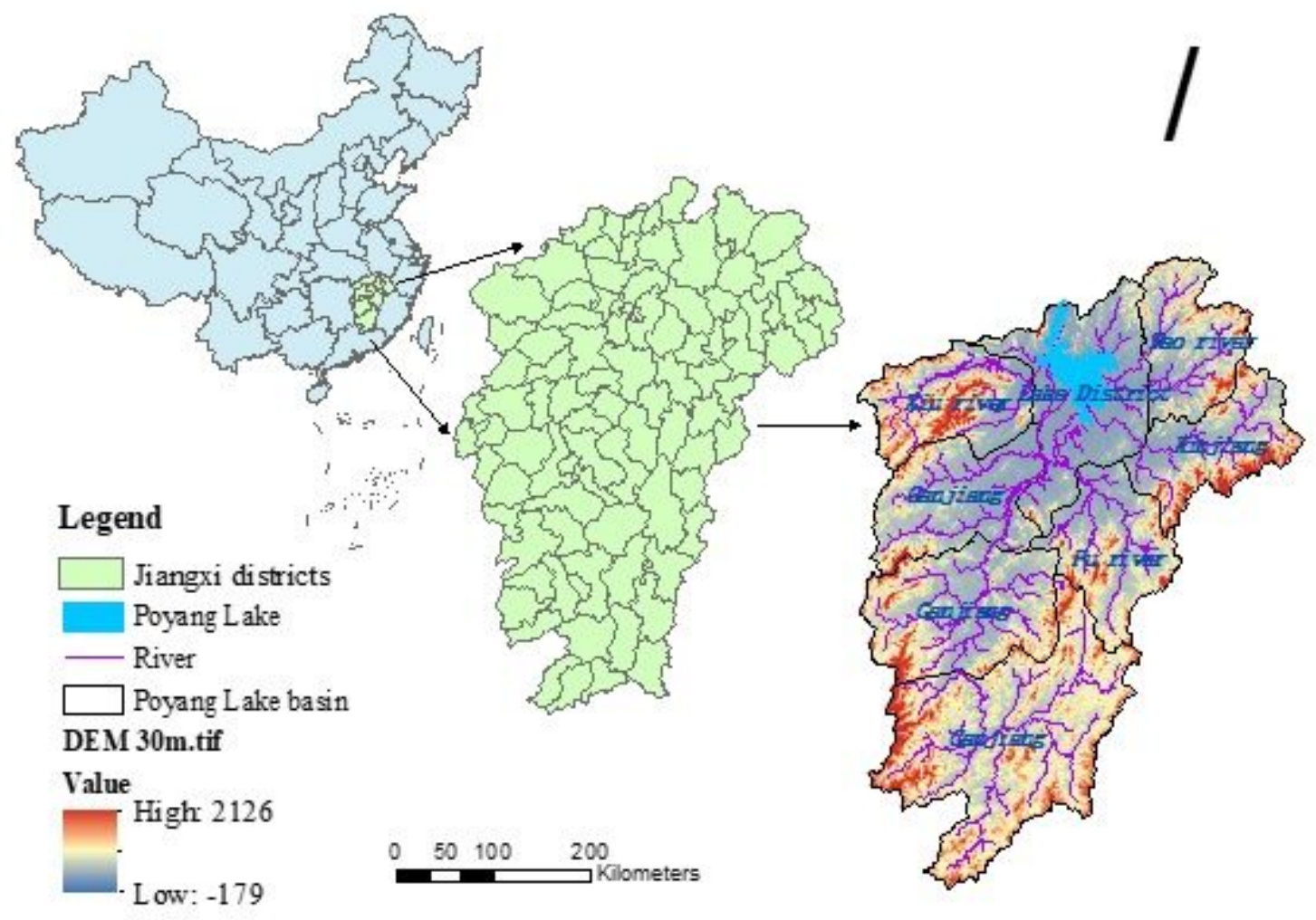

\section{Figure 1}

Geographical Location of Jiangxi Province. Note: The designations employed and the presentation of the material on this map do not imply the expression of any opinion whatsoever on the part of Research Square concerning the legal status of any country, territory, city or area or of its authorities, or concerning the delimitation of its frontiers or boundaries. This map has been provided by the authors. 

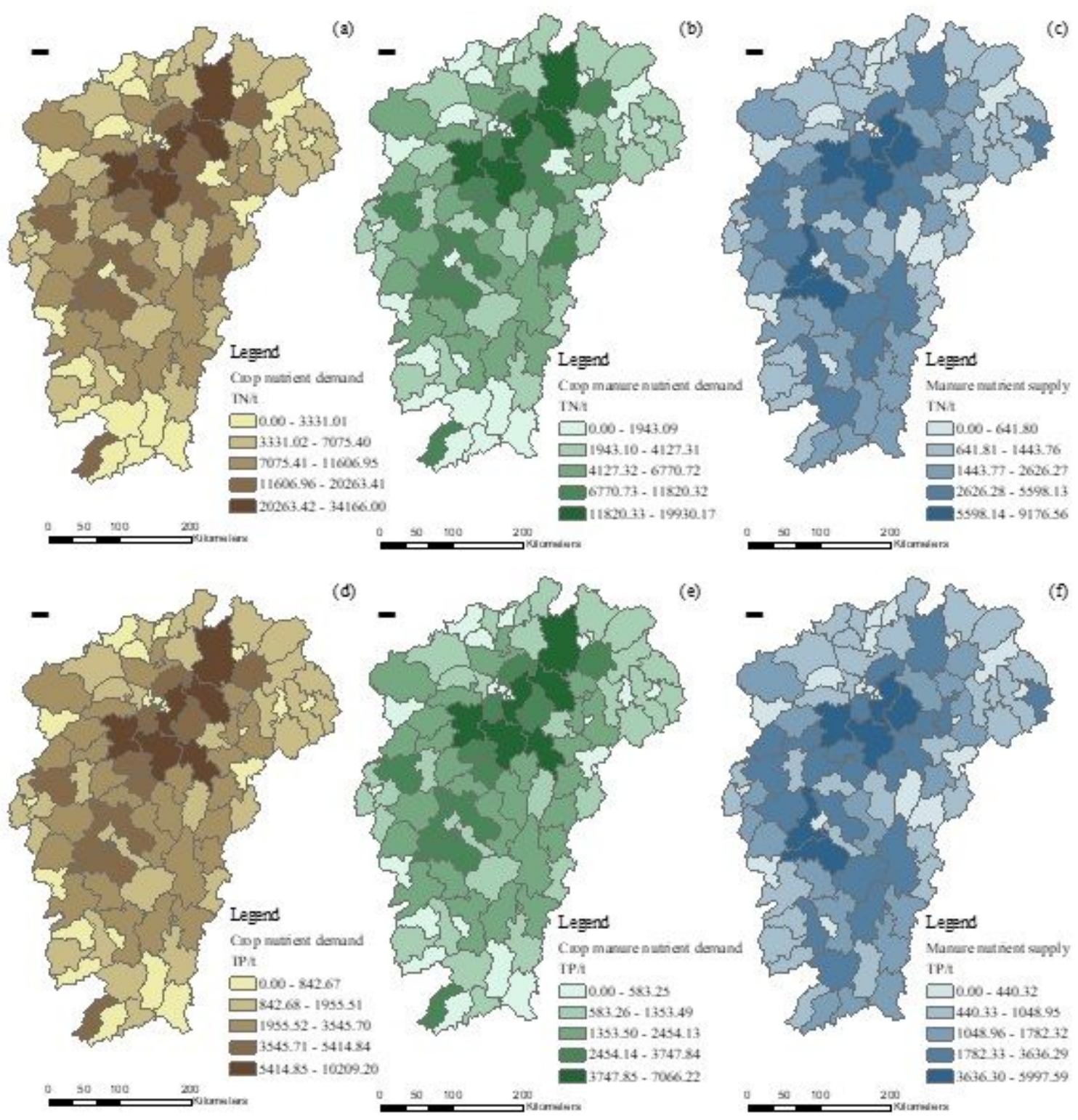

(d)
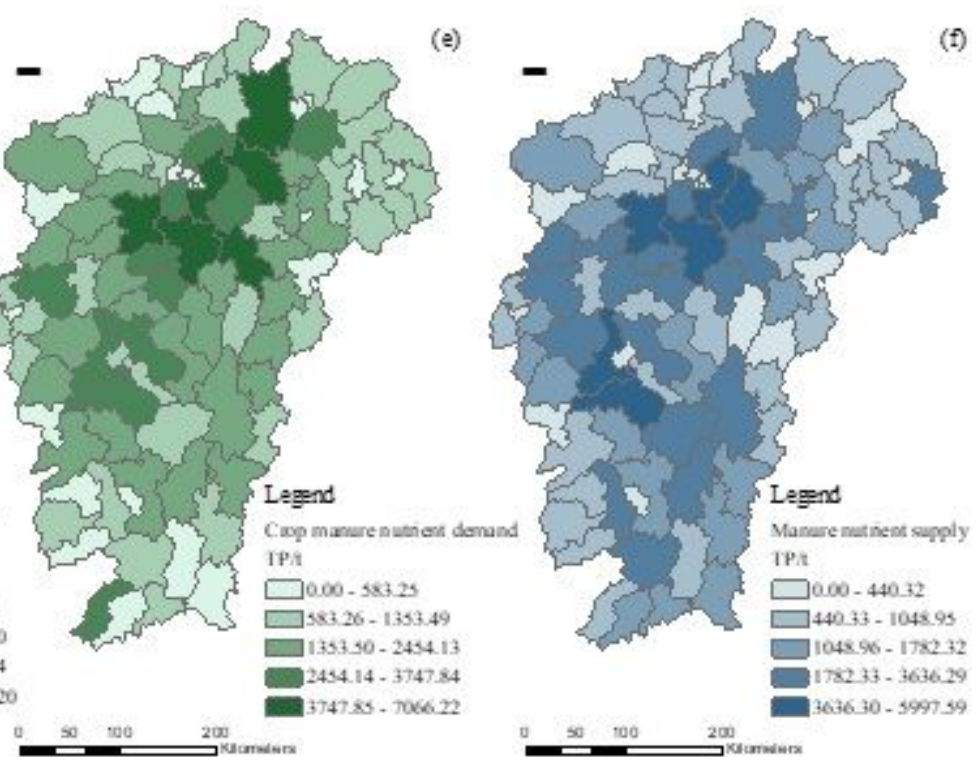

Figure 2

The crop nitrogen and phosphorus nutrient demands are shown in (a) and (d); the manure nitrogen and phosphorus nutrient demands for crop growth are shown in (b) and (e); and the manure nitrogen and phosphorus nutrient supplies are shown in (c) and (f). Note: The designations employed and the presentation of the material on this map do not imply the expression of any opinion whatsoever on the part of Research Square concerning the legal status of any country, territory, city or area or of its authorities, or concerning the delimitation of its frontiers or boundaries. This map has been provided by the authors. 


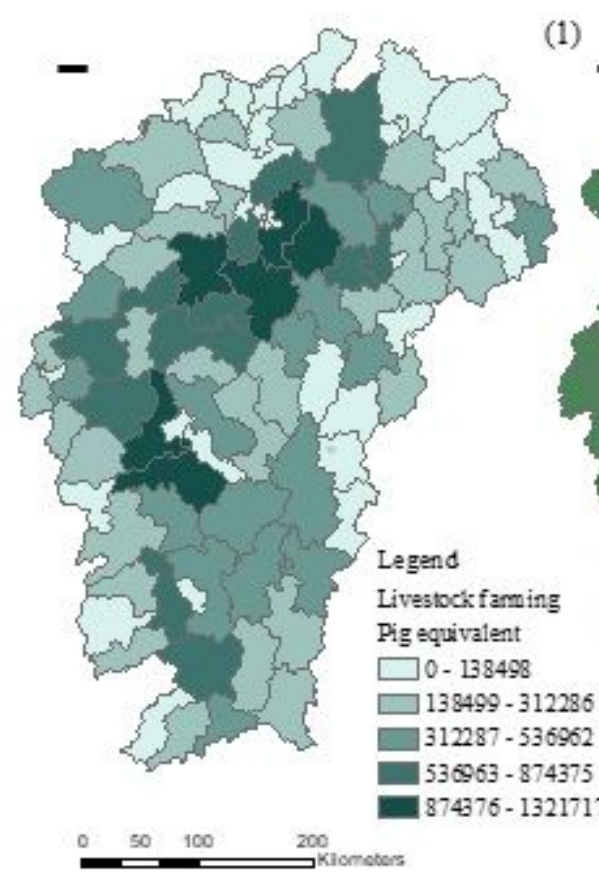

(1)

(2)

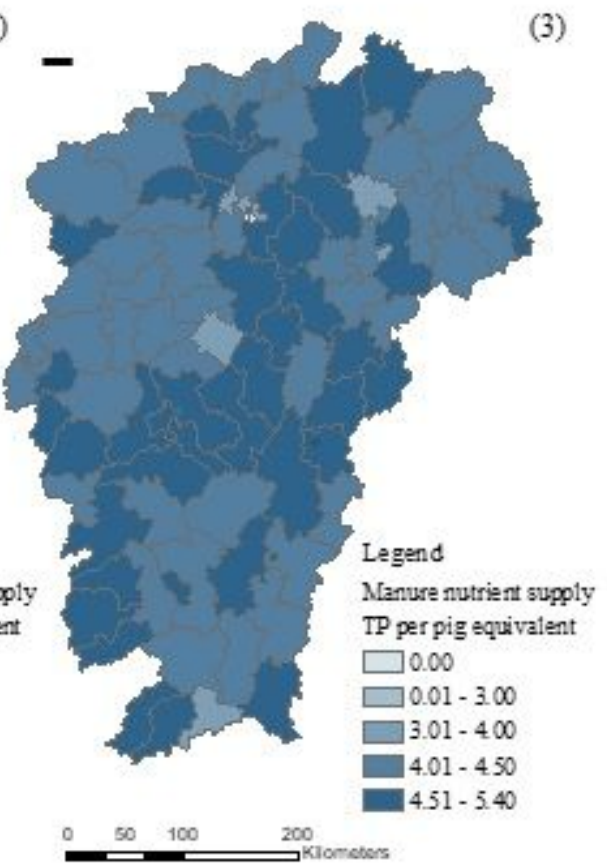

Figure 3

The final inventory of each district and county converted to pig equivalent units in 2016 is shown in (1); the nitrogen and phosphorus nutrient contents per pig equivalent are shown in (2) and (3), respectively. Note: The designations employed and the presentation of the material on this map do not imply the expression of any opinion whatsoever on the part of Research Square concerning the legal status of any country, territory, city or area or of its authorities, or concerning the delimitation of its frontiers or boundaries. This map has been provided by the authors.
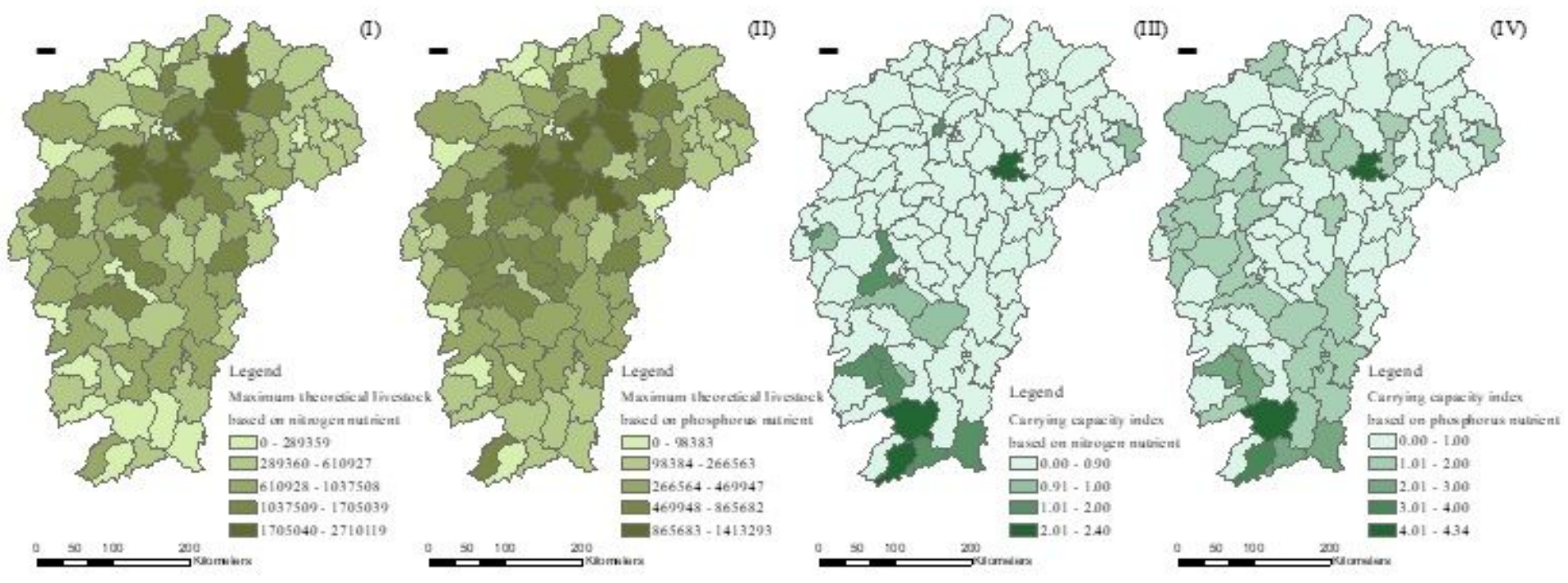

Figure 4 
The theoretical maximum livestock based on the land carrying capacity and considering nitrogen and phosphorus nutrition are shown in (I) and (II); the carrying capacity indexes considering nitrogen and phosphorus nutrition are shown in (III) and (IV), respectively. Note: The designations employed and the presentation of the material on this map do not imply the expression of any opinion whatsoever on the part of Research Square concerning the legal status of any country, territory, city or area or of its authorities, or concerning the delimitation of its frontiers or boundaries. This map has been provided by the authors.
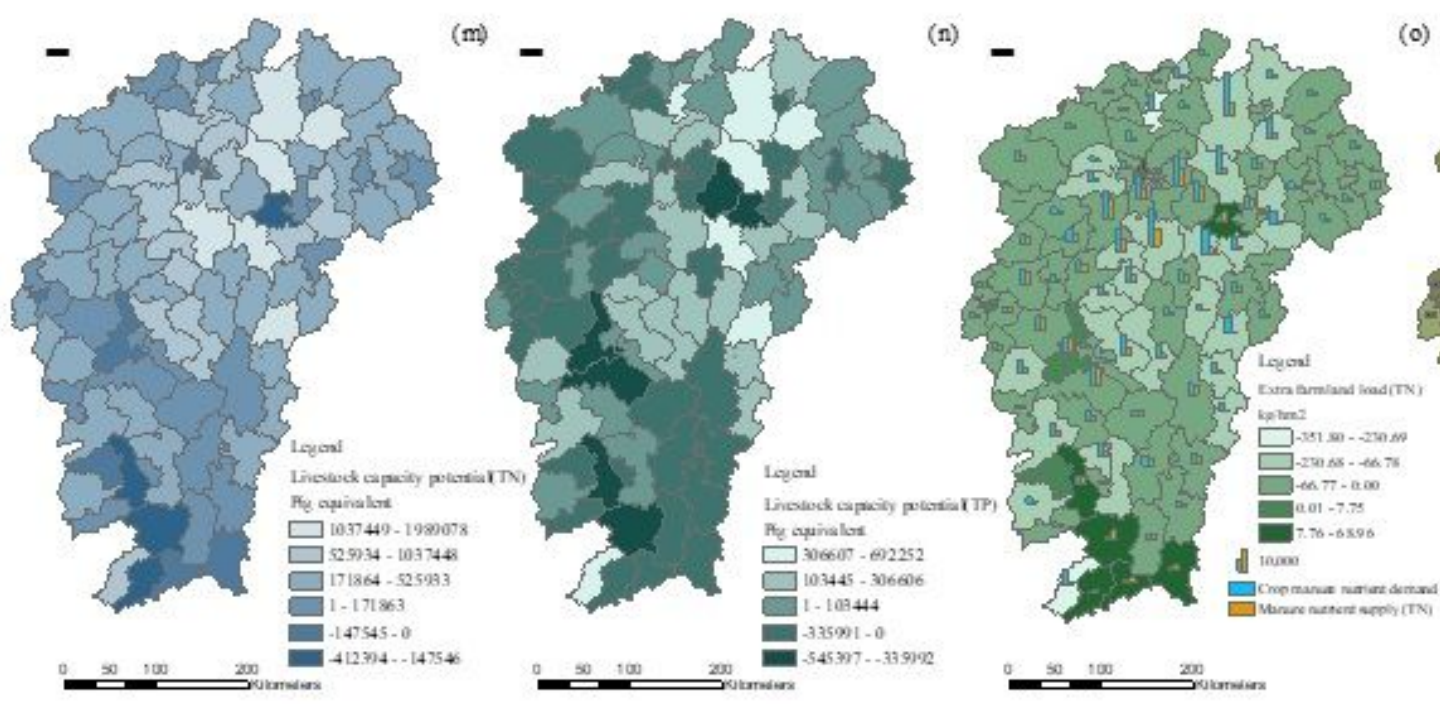

(o)

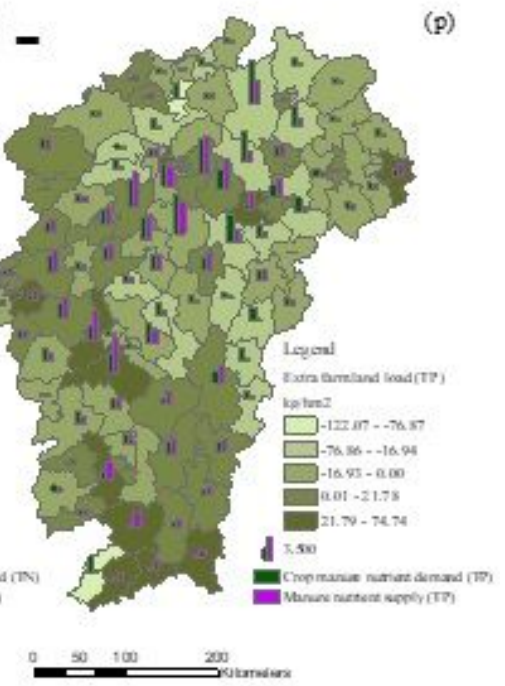

\section{Figure 5}

The breeding potential of livestock and poultry based on the calculation of nitrogen and phosphorus nutrient demand and supply are shown in $(m)$ and $(n)$ (pig equivalent). The excess units of farmland loads of nitrogen and phosphorus nutrients in each district are shown in (o) and (p), kg/hm2. Note: The designations employed and the presentation of the material on this map do not imply the expression of any opinion whatsoever on the part of Research Square concerning the legal status of any country, territory, city or area or of its authorities, or concerning the delimitation of its frontiers or boundaries. This map has been provided by the authors.
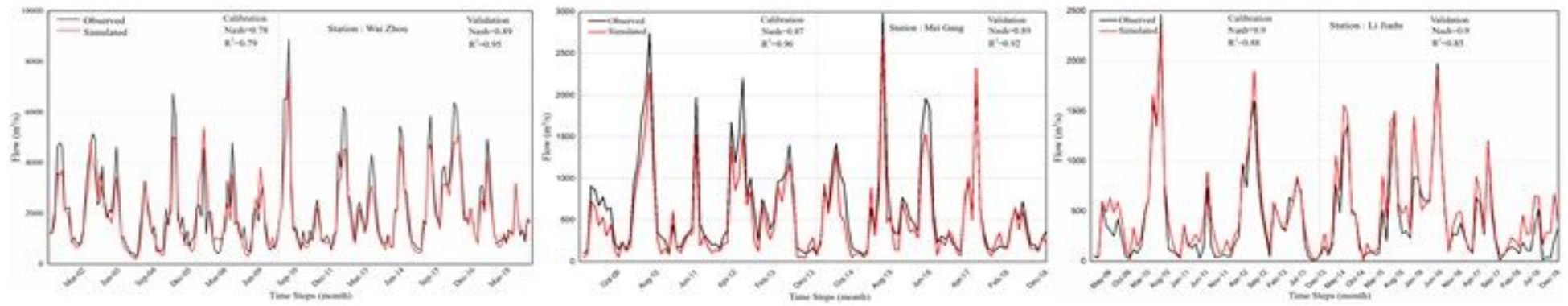

\section{Figure 6}

Results of hydrological calibration and validation in the Ganjiang, Xinjiang and Fu Rivers. 

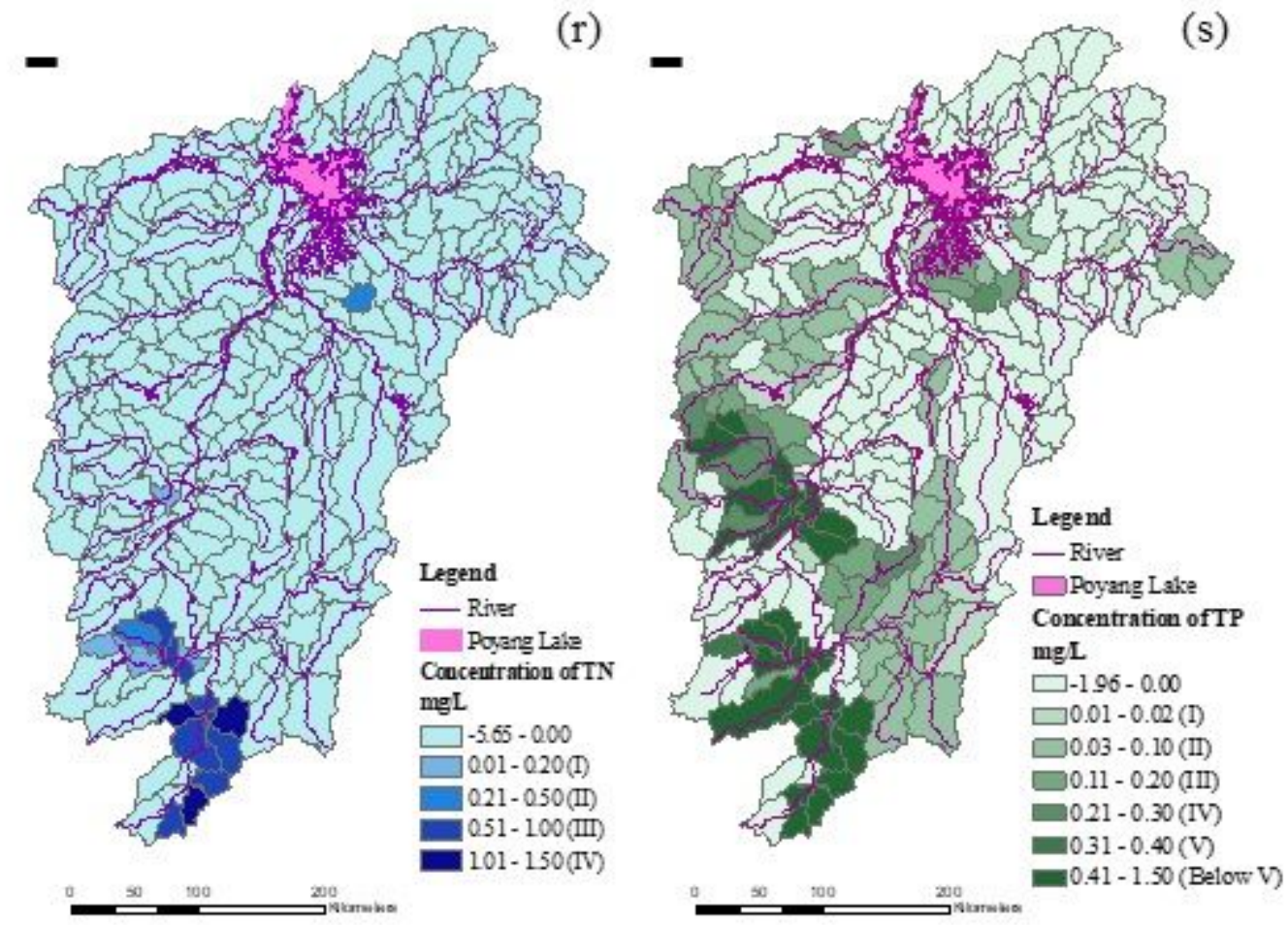

Figure 7

The distribution of nitrogen and phosphorus concentrations in the water environment under additional livestock manure loads are shown in ( $r$ ) and (s), respectively. Note: The designations employed and the presentation of the material on this map do not imply the expression of any opinion whatsoever on the part of Research Square concerning the legal status of any country, territory, city or area or of its authorities, or concerning the delimitation of its frontiers or boundaries. This map has been provided by the authors. 


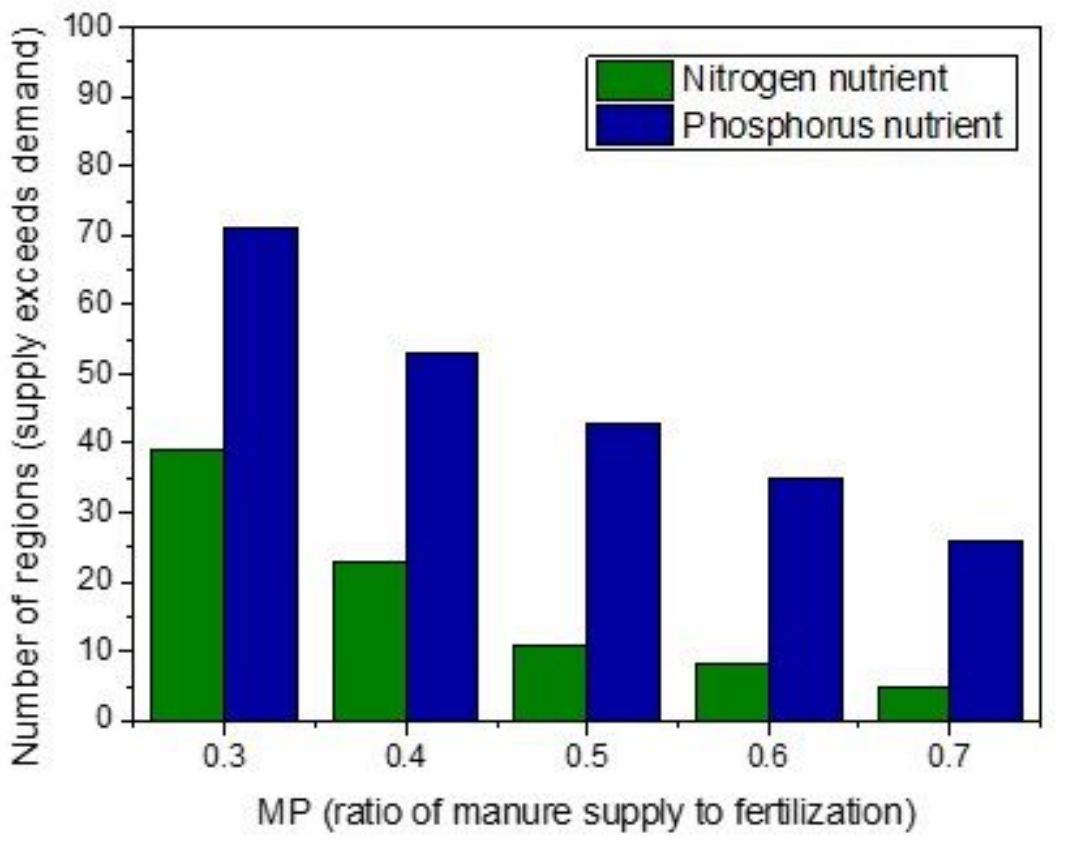

\section{Figure 8}

The number of districts exceeding the land carrying capacity under different ratios of manure supply to fertilization.
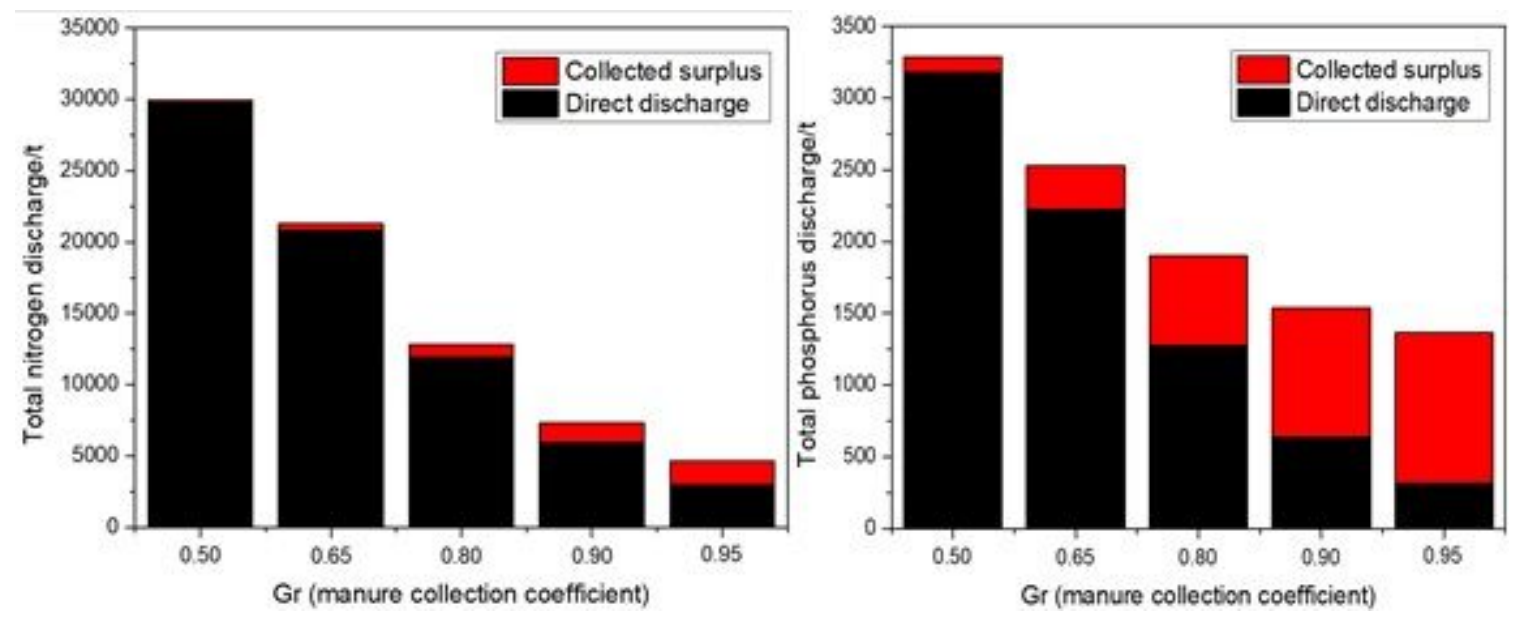

Figure 9

Discharge amounts of total nitrogen and total phosphorus under different manure collection coefficients.

\section{Supplementary Files}

This is a list of supplementary files associated with this preprint. Click to download.

- Supplementarymaterials.docx 